\title{
RESPONSABILIDADE SOCIAL \\ EMPRESARIAL RELACIONADA AO TRABALHO DE DEFICIENTES FISICOS
}

\section{CORPORATE SOCIAL RESPONSIBILITY RELATED TO THE WORK OF DISABLED PEOPLE}

\author{
Alexandre Antonio Bruno da Silva \\ alexandre_bruno@terra.com.br \\ Vanessa Guimarães Romão \\ by_vanessaguimaraes@gmail.com
}

Recebido: 30-9-2017

Aprovado: 2-6-2019

SUMÁRIO: 1 Introdução. 20 caminho do misticismo ao reconhecimento e inclusão. 3 A deficiência fisica sob o aspecto jurídico. 40 Brasil e a inclusão. 5 Considerações finais. 6 Referências.

\section{RESUMO:}

O presente trabalho tem por objetivo relatar e analisar as ações de responsabilidade social na inclusão de deficientes no mercado de trabalho. A metodologia utilizada para este estudo foi o método exploratório, com base em pesquisas bibliográficas, somadas à pesquisa de campo. Foi utilizado como instrumento de pesquisa um questionário, com os colaboradores portadores de deficiência física, que participam ativamente do mercado de trabalho. $\mathrm{O}$ artigo promove uma reflexão fundamental sobre as novas lógicas de atuação das empresas privadas em meio às ausências e lacunas do Estado democrático na inclusão de deficientes. Constata-se que não existem ações sólidas de responsabilidade social para com os colaboradores deficientes, por não serem contemplados com

\section{ABSTRACT:}

This paper aims to report and analyze social responsibility actions in the inclusion of the disabled in the labor market. The methodology used for this study was the exploratory method, based on bibliographical research, added to field research. A questionnaire was used as a research tool, with employees with physical disabilities, who participate actively in the labor market. The article promotes a fundamental reflection on the new logic of action of private companies in the midst of the absences and gaps of the democratic State in the inclusion of the disabled. It is noted that there are no solid actions of social responsibility towards disabled employees, because they are not covered by 
os cuidados e direitos necessários e previstos na Legislação.

\section{Palavras-chave:}

Responsabilidade social; Deficiência física; Deficientes físicos. the necessary care and rights provided in the Legislation.

\section{Keywords:}

Social Responsibility; Disability; Disabled people.

\section{INTRODUÇÃO}

A responsabilidade social empresarial (RSE) vem, nos últimos anos, se tornando um tema muito debatido nos meios acadêmicos e empresariais (SOUSA FILHO; WANDERLEY, 2006). Seguindo uma tendência mundial, as empresas no Brasil estão cada vez mais preocupadas com o assunto. Sendo assim, elas passaram a contemplar mudanças organizacionais com implicaçóes estratégicas profundas, partindo da premissa de que, para serem efetivas, tais mudanças devem estar alinhadas com a estratégia de negócios da empresa. (COUTINHO; MACEDO-SOARES, 2002).

Segundo Mintzberg (1983), a responsabilidade social torna-se indispensável porque as decisóes estratégicas de grandes empresas envolvem tanto consequências econômicas quanto sociais, já que estas estão inexoravelmente interligadas. Na mesma perspectiva, Porter; Kramer (2006) argumentaram que existe uma interdependência entre as empresas e a sociedade, já que as atividades da cadeia de valor das companhias impactam diretamente as comunidades em que estas operam, podendo gerar consequências positivas ou negativas.

A Organização Mundial da Saúde (OMS) trabalha com a estimativa de que, em todo país não envolvido em guerra, deve haver hoje em dia cerca de $10 \%$ da população com alguma deficiência física, visual, auditiva ou mental. O Brasil deveria ter, portanto, algo em torno de 17 milhões de pessoas deficientes. Mas, segundo os dados oficiais do Instituto Brasileiro de Geografia e Estatística (IBGE) publicados no Censo de 2000, temos aproximadamente 24,5 milhóes, ou seja, $4,5 \%$ a mais do que a média dos outros países.

Empresas contratam pessoas com deficiência, profissionalmente qualificadas, quer porque atuam com responsabilidade social empresarial, quer porque precisam atender as cotas de emprego determinadas pela legislação atual. Aumentou então a procura por pessoas com deficiência profissionalizadas. Mas aquela maioria que não tem qualificação profissional continua à margem do mercado de trabalho, sem emprego, sem dinheiro e, consequentemente, sem qualidade de vida.

Neste sentido, este artigo justifica-se pela pouca produção acadêmica nacional relacionando à área de Responsabilidade Social Empresarial (RSE) com relação ao trabalho de deficientes físicos. Desse modo, estudar este tema é importante para o crescimento da área e alargamento do debate em torno dessa temática, a fim de gerar novas teorias, formas de pensar. Assim, este trabalho visa contribuir não só para retratar as ações de responsabilidade social atreladas ao trabalho de colaboradores com deficiência física do hospital em questão, como também somar na produção acadêmica sobre a relação intrínseca existente entre a RSE e colaboradores deficientes físicos. 
Consegue-se dimensionar o entendimento social sobre o indivíduo deficiente, reportando-se, de certa forma, ao passado e localizando nas diferentes épocas o retrato que se formou, culturalmente, sobre a ideia das diferenças individuais.

\section{O CAMINHO DO MISTICISMO AO RECONHECIMENTO E INCLUSÃO}

Silva (1987, apud CARMO, 1991) expóe que nas culturas dos povos primitivos, apesar de existir todo um crédito às forças sobrenaturais (animismo) e às práticas de feitiçaria, não houve, para certas tribos, a atribuição de defeitos físicos a algum tipo de magia. Este estudioso cita os membros da tribo Xangga (da Tanzânia/África), que "não prejudicavam ou matavam as crianças ou adultos com deficiência. Acreditavam que os maus espíritos habitavam essas pessoas e nelas arquitetavam e se deliciavam para tornar possível a todos os demais membros a normalidade".

Mazzotta (2001, p. 16) em sua análise histórica, diz que “(...) até o século XVIII, as noçóes a respeito de deficiência eram basicamente ligadas ao misticismo e ocultismo, não havendo base científica para o desenvolvimento de noçóes realísticas”. Segue o autor esclarecendo que foi na Europa que se deram os movimentos pioneiros em favor do indivíduo deficiente.

Figueira (2008) realiza trajetória semelhante àquela de Silva (1987, apud CARMO, 1991), mas concentra-se na história do Brasil. Este autor propóe que seu livro marque uma introdução à história das pessoas com deficiência no país, definindo também sua tese principal, que diz: "as questóes que envolvem as pessoas com deficiência no Brasil - por exemplo, mecanismos de exclusão, políticas de assistencialismo, caridade, inferioridade oportunismo, dentre outras - foram construídas culturalmente" (FIGUEIRA, 2008, p. 17).

Essas questôes culturais requerem tempo relevante para serem desconstruídas, e é esse o movimento que tem se formado pelas pessoas com deficiência e organizaçóes representativas nas últimas décadas.

\section{A DEFICIÊNCIA FÍSICA SOB O ASPECTO JURÍDICO}

Visando à proteção específica da pessoa com deficiência, a Assembleia Geral da ONU proclamou duas importantes Declaraçóes e uma Resolução, na década de 1970: a Declaração dos Direitos das Pessoas com Retardo Mental, em 1971; a Declaração dos Direitos das Pessoas Deficientes, em 1975; e a Resolução no 31/123, em 1976, declarando o ano de 1981 como o Ano Internacional das Pessoas Deficientes.

Se até aqui a pessoa com deficiência caminhou em silêncio, excluída ou segregada em entidades, a partir de 1981 - Ano Internacional da Pessoa Deficiente -, tomando consciência de si, passou a se organizar politicamente. E, como consequência, a ser notada na sociedade, atingindo significativas conquistas em pouco mais de 25 anos de militância (FIGUEIRA, 2008, p. 115).

A Declaração dos Direitos das Pessoas Deficientes, de 09 de dezembro de 1975, teve sua relevância por trazer o conceito de "pessoa deficiente", assim como influenciar na concepção da expressão "pessoa portadora de deficiência", utilizada pela Constituição Federal de 1988. Segundo ela, a pessoa deficiente seria aquela incapaz de satisfazer por si própria, 
no todo ou em parte, as necessidades de uma vida normal individual ou social, em resultado de deficiência, congênita ou não, nas suas faculdades físicas ou mentais.

O Ano Internacional das Pessoas Deficientes (AIPD) foi de grande importância, servindo para que países, seus governantes, a sociedade e as próprias pessoas com deficiência, tomassem consciência da relevância do tema. Fazia-se necessária, há tempos, a tomada de providências para a prevenção da deficiência, a reabilitação, a acessibilidade, a igualdade de condições, a participação plena e a mudança de valores sociais, visando à redução crescente de preconceitos e atitudes discriminatórias.

O AIPD foi em 1981, mas o início do processo se deu em 1976, ano este em que a ONU o proclamou durante a $31^{\text {a }}$ sessão da Assembleia Geral, com tema: "Participação Plena". Os alvos principais do AIPD com relação às pessoas deficientes eram: auxiliar no ajustamento psicossocial e físico na sociedade; promover esforços, internacional e nacionalmente, viabilizando o trabalho compatível e a total integração à sociedade; encorajamento dos projetos de estudo e pesquisa, visando a integração às atividades do cotidiano, aos edifícios públicos e aos transportes; informar e educar o público sobre os direitos de participar e contribuir nos vários aspectos da vida social, econômica e política.

Esse reconhecimento, expresso no Ano Internacional da ONU para Pessoas Deficientes, representa a mudança no tratamento do tema da deficiência pelos organismos internacionais. Essa guinada política foi promovida, por um lado, pelo ativismo político dos movimentos sociais e organizaçôes de deficientes, que lutaram contra todas as formas de opressão, e por outro, pela entrada dos estudos sobre deficiência no meio acadêmico. (BARTON; OLIVER, 1997, p. 280).

No âmbito das Américas, tem-se a Convenção Interamericana para a Eliminação de Todas as Formas de Discriminação contra as Pessoas Portadoras de Deficiência, conhecida como Convenção da Guatemala, assinada pelo Brasil em 1999, promulgada pelo Decreto n. ${ }^{\circ} 3.956$, de 08 de outubro de 2001. Incorporada ao sistema legislativo brasileiro com status de lei ordinária, define o termo "deficiência" como uma restrição física, mental ou sensorial, de natureza permanente ou transitória, que limita a capacidade de exercer uma ou mais atividades essenciais da vida diária, causada ou agravada pelo ambiente econômico e social.

No Brasil, essa Convenção foi aprovada por meio do Decreto Legislativo no 186 , de 9 de julho de 2008 , conforme o procedimento previsto no $\$ 3^{\circ}$ do art. $5^{\circ}$ da Constituição, obtendo equivalência de emenda constitucional. O Governo brasileiro depositou o instrumento de ratificação dos referidos atos junto ao Secretário-Geral das Naçóes Unidas em $1^{\circ}$ de agosto de 2008. A Convenção foi promulgada pelo Decreto 6.949, de 25 de agosto de 2009.

A Emenda Constitucional n. ${ }^{\circ}$ 45, de 31 de dezembro de 2004, acrescentou o parágrafo terceiro ao artigo quinto, cuja redação trata dos tratados e convenções sobre direitos humanos: " $\$ 3^{\circ}$ Os tratados e convençóes internacionais sobre direitos humanos que forem aprovados, em cada Casa do Congresso Nacional, em dois turnos, por três quintos dos votos dos respectivos membros, serão equivalentes às emendas constitucionais" (BRASIL, 2004).

A adoção dessa Convenção resulta do consenso da comunidade internacional sobre a necessidade de garantir o respeito pela integridade, dignidade e liberdade das pessoas com deficiência. Devem ser criadas leis, políticas e programas que atendam ao público deficiente 
dentro de suas características, promovendo a sua participação na sociedade e buscando a sensibilização dos demais membros da sociedade para esse processo de inclusão.

\section{O BRASIL E A INCLUSÃO}

O Brasil é um dos poucos países que tem legislação específica tratando dos deficientes. Apesar disso, os deficientes brasileiros continuam a compor o grupo com percentuais mais elevados nas estatísticas de exclusão social. Essa realidade é confirmada pela baixa presença de pessoas com deficiência nos setores básicos que promovem a inclusão.

Os números relativos ao acesso ao trabalho comprovam essa realidade. Inicialmente será apresentada a legislaçâo protetiva no âmbito do direito trabalhista, e posteriormente os dados estatísticos.

Nossa Constituição proíbe qualquer discriminação no tocante à salário e critérios de admissão do trabalhador portador de deficiência (art. 70, XXXI, CF). Em relação às vagas prevê que legislação complementar reservará percentual dos cargos e empregos públicos para as pessoas portadoras de deficiência e definirá os critérios de sua admissão (art. 37, CF).

Na Administração Pública Federal, a Lei no 8.112, de 11 de dezembro de 1990, que dispõe sobre o regime jurídico dos servidores públicos civis da União, assegurou o direito das pessoas com deficiência de se inscrever em concurso público para provimento de cargo, em igualdade de condiçóes com os demais candidatos, sendo-lhes reservadas até $20 \%$ das vagas oferecidas no concurso (artigo $5^{\circ}, \$ 2^{\circ}$ ).

O Decreto no 3.298, de 20 de dezembro de 1999, estabelece que o percentual mínimo é de $5 \%$ de reserva das vagas nos concursos públicos ( $\$ 1^{\circ}$ do artigo 37 ), aplicando o arredondamento para o primeiro número inteiro subsequente, quando o resultado do percentual resultar em número fracionado $\left(\$ 2^{\circ}\right)$.

$\mathrm{Na}$ esfera privada, a reserva de vagas é determinada quando a empresa possua $100 \mathrm{ou}$ mais empregados. Além desta cota - de 2 a 5\% das vagas, dependendo da quantidade de trabalhadores - as empresas não podem efetivar dispensa imotivada, quando esta representar o número mínimo de trabalhadores com deficiência que a empresa deve possuir, até a contratação de substituto em condiçóes semelhantes ( $\$ 1^{\circ}$ do artigo 93 da Lei no 8.213/91). Condição semelhante significa que outro trabalhador com deficiência ou reabilitado deverá ser contratado, não sendo, necessariamente, trabalhador com a mesma deficiência do substituto ou para a mesma função ou cargo.

A Lei no 7.853 , de 24 de outubro de 1989 , em seu artigo $8^{\circ}$, tipificou como crime punível com reclusão de 01 (um) a 04 (quatro) anos, quem obstar, sem justa causa, o acesso de alguém a qualquer cargo público ou negar a alguém emprego ou trabalho, por motivos derivados de sua deficiência.

No contexto da responsabilidade social das empresas, insere-se, entre outras, a obrigação de contribuir e apoiar a qualificação de seus empregados. É nesse sentido que o Estado brasileiro procurou aprimorar a legislação da aprendizagem para incentivar a promoção da qualificação profissional pelos próprios empregadores.

A alteração foi promovida pela Medida Provisória no 251, de 13 de junho de 2005, posteriormente convertida na Lei no 11.180 , de 23 de setembro de 2005 , com a inserção do $\$ 5^{\circ}$ ao artigo 428 da Consolidação das Leis Trabalhistas - CLT, que prevê a possibilidade 
de as empresas contratarem aprendizes com deficiência independente do limite de idade, quando para os demais segmentos da população, o limite é de 24 anos.

A lei permite a contratação de aprendizes no percentual de 5 a 15\%, calculado sobre o número de trabalhadores cujas funções demandassem formação profissional. As empresas podiam, portanto, contratar pessoas com deficiência na cota de aprendizes para, posteriormente, contratá-las como empregados por prazo indeterminado, na forma da lei específica, já devidamente qualificada.

Apesar da importância das medidas legislativas anteriores, a Lei no 13.146, de 6 de julho de 2015, que institui a Lei Brasileira de Inclusão da Pessoa com Deficiência (Estatuto da Pessoa com Deficiência) é o mais completo diploma que trata da inclusão do deficiente em nosso país.

De acordo com o texto, é classificada como pessoa com deficiência aquela que tem impedimentos de longo prazo de natureza física, mental, intelectual ou sensorial que podem obstruir sua participação plena e efetiva na sociedade em igualdade de condições com as demais pessoas.

A tônica do texto, que conta com mais de 100 artigos, é a inclusão social das pessoas com deficiência, que deve ser oportunizada por meio de políticas públicas ou iniciativas a cargo das empresas.

No âmbito trabalhista, o Estatuto da Pessoa com Deficiência (EPD) estabelece que constitui modo de inclusão da pessoa com deficiência no trabalho a colocação competitiva, em igualdade de oportunidades com as demais pessoas, nos termos da legislação trabalhista e previdenciária, na qual devem ser atendidas as regras de acessibilidade, o fornecimento de recursos de tecnologia assistiva e a adaptação razoável no ambiente de trabalho.

A colocação competitiva da pessoa com deficiência pode ocorrer por meio de trabalho com apoio, observadas como diretrizes: a) o atendimento prioritário à pessoa com deficiência com maior dificuldade de inserção no campo de trabalho; b) provisão de suportes individualizados que atendam a necessidades específicas da pessoa com deficiência; c) respeito ao perfil vocacional e ao interesse da pessoa com deficiência apoiada; d) oferta de aconselhamento e de apoio aos empregadores, com vistas à definição de estratégias de inclusão e de superação de barreiras, inclusive atitudinais; e) realizaçâo de avaliações periódicas; $\mathrm{f}$ ) articulação intersetorial das políticas públicas; g) possibilidade de participação de organizaçóes da sociedade civil.

Um dos pontos relevantes no âmbito trabalhista foi a manutenção do direito ao auxílio-inclusão para a pessoa com deficiência moderada ou grave que passe a ter atividade remunerada. Assim, terá direito a auxílio-inclusão, a pessoa que receba o benefício de prestaçáo continuada e que passe a exercer atividade remunerada que a enquadre como segurado obrigatório do Regime Geral da Previdência Social (RGPS).

Além desses, também é devido àquele que tenha recebido, nos últimos 5 (cinco) anos, o benefício de prestação continuada e que exerça atividade remunerada que a enquadre como segurado obrigatório do Regime Geral da Previdência Social.

No art. 93, do Projeto de Lei 7.699/06, que deu origem ao EPD, havia a previsão de que empresas com 50 (cinquenta) ou mais empregados seriam obrigadas a preencher seus cargos com pessoas com deficiência. Empresas que tivessem entre 50 (cinquenta) entre 99 (noventa e nove) empregados deveriam ter pelo menos 1 (um) empregado deficiente. As empresas teriam o prazo de até 3 (três) anos até serem fiscalizadas. 
Entretanto, esse dispositivo foi vetado, apesar do mérito da proposta, por se acreditar que a medida poderia gerar impacto relevante no setor produtivo, especialmente para empresas de mão de obra intensiva de pequeno e médio porte, acarretando dificuldades no seu cumprimento e aplicação de multas que poderiam inviabilizar empreendimentos de ampla relevância social. A obrigatoriedade persistiu apenas para empresa com mais de 100 (cem) empregados.

Para estimular a aplicabilidade do sistema, foi alterada a Lei de Licitaçóes (Lei 8.666/93), para permitir o uso de margens de preferência nas licitaçóes para as empresas que comprovem bens e serviços produzidos ou prestados por empresas que comprovem cumprimento de reserva de cargos prevista em lei para pessoa com deficiência ou para reabilitado da Previdência Social e que atendam às regras de acessibilidade previstas na legislação.

As empresas enquadradas estão obrigadas a cumprir, durante todo o período de execução do contrato, a reserva de cargos prevista em lei para pessoa com deficiência ou para reabilitado da Previdência Social, bem como as regras de acessibilidade previstas na legislação. Cabe à administração fiscalizar o cumprimento dos requisitos de acessibilidade nos serviços e nos ambientes de trabalho. (art. 104, do EPD).

Por fim, importante assinalar que o EPD estabeleceu que somente a contratação direta será contada, excluído a possibilidade de cumprimento de cota, através da contratação de aprendiz com deficiência de que trata a Consolidação das Leis do Trabalho (CLT), aprovada pelo Decreto-Lei no 5.452 , de $1^{\circ}$ de maio de 1943.

Além disso, o EPD criou o Cadastro Nacional da Inclusão da Pessoa com Deficiência com a finalidade de coletar e processar informaçóes destinadas à formulação, gestão, monitoramento e avaliação das políticas públicas para as pessoas com deficiência e para a realização de estudos e pesquisas. O Cadastro-Inclusão, é registro público eletrônico, que deverá disseminar informaçóes georreferenciadas que permitam a identificação e a caracterização socioeconômica da pessoa com deficiência, bem como das barreiras que impedem a realização de seus direitos.

Instrumento de verificação da ocupação das vagas de emprego por parte dos deficientes. O relatório da RAIS classifica os tipos de deficiência em: a) física; b) auditiva; c) visual; d) intelectual d) múltipla e f) reabilitado.

Tabela 1 - Deficientes empregados no Brasil por tipo de deficiência

\begin{tabular}{cccc}
\hline Tipo & 2012 & 2013 & Variação \\
\hline Física & 170.468 & 181.464 & 6,45 \\
Auditiva & 74.385 & 78.078 & 4,96 \\
Visual & 26.119 & 33.505 & 28,28 \\
Intelectual & 21.317 & 25.332 & 18,83 \\
Múltipla & 4.696 & 5.490 & 16,91 \\
Reabilitado & 33.311 & 33.928 & 1,85 \\
Totais & 330.296 & 357.797 & 8,33 \\
\hline
\end{tabular}

Fonte: RAIS (2012;2013). 
Gráfico 1 - Deficientes empregados no Brasil por tipo de deficiência no ano de 2013

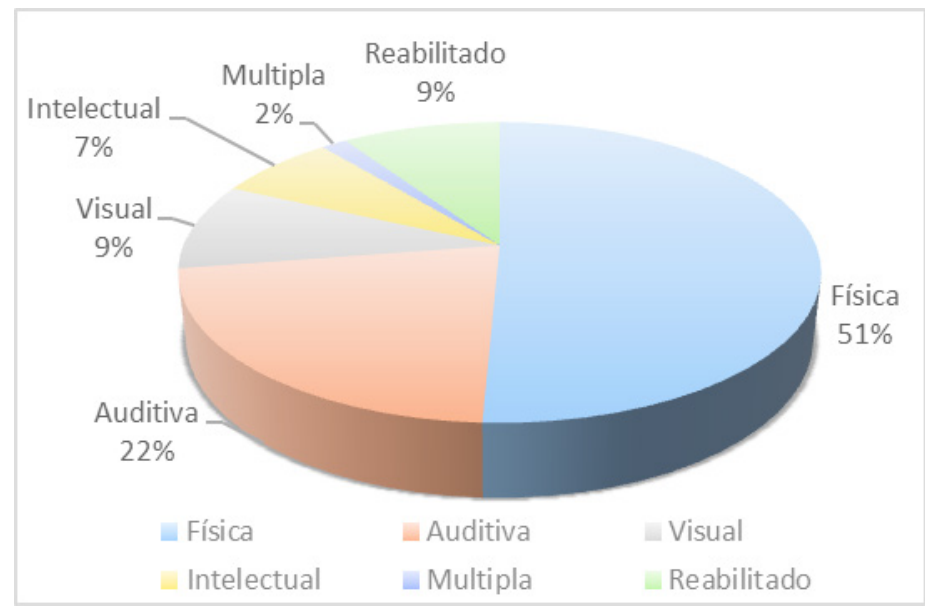

Fonte: Elaborado pelo autor.

Tabela 2 - Deficientes empregados no Ceará por tipo de deficiência.

\begin{tabular}{cccc}
\hline Tipo & 2012 & 2013 & Variação \\
\hline Física & 7.645 & 8.346 & 9,17 \\
Auditiva & 2.182 & 2.370 & 8,62 \\
Visual & 976 & 1.227 & 25,72 \\
Intelectual & 229 & 263 & 14,85 \\
Múltipla & 98 & 112 & 14,29 \\
Reabilitado & 1.005 & 1.050 & 4,48 \\
Totais & 12.135 & 13.368 & 10,16 \\
\hline
\end{tabular}

Fonte: RAIS (2012; 2013).

Gráfico 2 - Deficientes empregados no Ceará por tipo de deficiência no ano de 2013

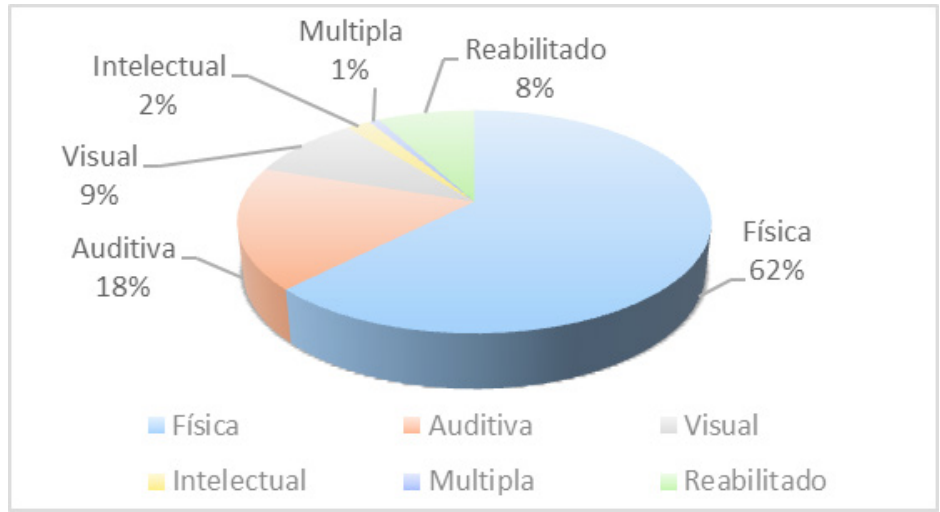

Fonte: Elaborado pelo autor. 
Em 2013, verificou-se no Brasil um aumento de 8,33 \%no número de pessoas declaradas como deficientes (PCD). O que representou um acréscimo de 10.996 vínculos, totalizando 357.797 vínculos, declarados no ano. No Estado do Ceará, no mesmo período, tivemos um incremento de $10,16 \%$, maior que a média nacional, representando um acréscimo de 1.233 empregos, totalizando 13.368 vínculos.

Interessante observar que em termos de Brasil, no ano de 2012, os deficientes ocupavam $0,70 \%$, subindo para $0,73 \%$ dos vínculos empregatícios. O Estado do Ceará apresenta um número de deficientes incluídos maiores que a média nacional com 0,85\% de vagas em 2012 e 0,89 no ano de 2013.

\section{Tabela 3 - Atividade do Ministério do Trabalho e Previdência Social}

\begin{tabular}{cccc}
\hline & 2012 & 2013 & 2014 \\
\hline Açóes Fiscais & 538 & 577 & 538 \\
PCD & 1.594 & 2.359 & 1.885 \\
Aprendizes & & 104 & 103 \\
\hline
\end{tabular}

Fonte: SFITWEB (2015).

Tabela 4 - Cota obrigatória de empregados com deficiência por empresa.

\begin{tabular}{cc}
\hline N Empregados & Cota $(\%)$ \\
\hline $100-200$ & 2,0 \\
$201-500$ & 3,0 \\
$501-1000$ & 4,0 \\
$>1000$ & 5,0 \\
\hline
\end{tabular}

Fonte: Brasil, Lei 8.213/91.

Um dos projetos obrigatórios da auditoria fiscal do Ministério do Trabalho e Previdência Social é aquele que objetiva promover a inclusão de pessoas com deficiência e reabilitados no mercado de trabalho.

O termo inclusão, como já apresentado, segue a ideia geral de que o objetivo principal das açóes da auditoria, não é somente quantitativo. O objeto da ação fiscal nas empresas, com o fito de implementar a política pública governamental de inclusão dos deficientes, não se exaure apenas com o quantitativo de registros. Estende-se a uma análise qualitativa dos vínculos constituídos.

Devem ser observadas as especificidades das pessoas com deficiência e reabilitadas, verificando-se a adequação das atividades a serem exercidas em relação ao tipo de deficiência ou restrição apresentada. Além disso, é preciso verificar a existência do tratamento igualitário em relação aos demais empregados, evitando a discriminação na seleção, durante o contrato de trabalho e após a extinção do vínculo. Além disso, é preciso avaliar as condiçóes de trabalho.

Entretanto, por limitaçóes estruturais da auditoria, as ações fiscais são realizadas, quase exclusivamente, na modalidade indireta, abrangendo especificamente atributos diretamente relacionados ao registro dos empregados com deficiência-PCD. Na modalidade indireta a empresa é chamada à órgão local do Ministérios do Trabalho e Previdência Social, para comprovar que cumpre a cota determinada segundo os dispositivos legais. 
Além de ter como base as experiências dos anos anteriores, o projeto conta com o incremento de um sistema, que é capaz de relacionar um completo banco de empresas sujeitas à reserva legal de inclusão de pessoas com deficiência e reabilitadas do INSS. Através de uma simples consulta é capaz de se listar todas as empresas que estão aquém de suas cotas.

Tabela 5 - Empresas e cotas preenchidas

\begin{tabular}{|c|c|c|c|c|c|c|c|c|c|}
\hline $\begin{array}{l}\text { Porte da } \\
\text { empresa }\end{array}$ & $\begin{array}{c}\text { Número } \\
\text { de } \\
\text { empresas }\end{array}$ & $\begin{array}{c}\text { Empresas } \\
\text { inadimplentes }\end{array}$ & $\%$ & $\begin{array}{c}\text { Total } \\
\text { de } \\
\text { Cotas }\end{array}$ & $\begin{array}{c}\text { Cotas náo } \\
\text { preenchidas }\end{array}$ & $\%$ & $\begin{array}{c}\text { Total } \\
\text { empregados }\end{array}$ & $\begin{array}{c}\text { PCD } \\
\text { Contratados }\end{array}$ & $\%$ \\
\hline $100-200$ & 509 & 400 & 78,59 & 1.638 & 1.120 & 68,38 & 70.781 & 661 & 0,93 \\
\hline $201-500$ & 342 & 252 & 73,68 & 3.337 & 1.693 & 50,73 & 108.390 & 1.890 & 1,74 \\
\hline 501-1000 & 198 & 169 & 85,35 & 5.541 & 3.593 & 64,84 & 140.029 & 2.393 & 1,71 \\
\hline$>1000$ & 164 & 149 & 90,85 & 25.348 & 16.727 & 65,99 & 515.207 & 9.147 & 1,78 \\
\hline Totais & 1.213 & 970 & 79,97 & 35.864 & 23.133 & 64,50 & 834.407 & 14.091 & \\
\hline
\end{tabular}

Fonte: IDEB (2016)

Os dados da tabela acima foram extraídos do Sistema de Indícios de Débito do Ministério do Trabalho e Previdência Social (IDEB). Com isso, pretende-se alcançar o maior número possível de empresas e de PCD a serem inseridas no mercado de trabalho. Segundo o projeto, a área de abrangência engloba Fortaleza e Região Metropolitana, como também as regiôes do Cariri e Sobral, podendo ser incluídos outros municípios, observada a demanda local, bem como os recursos materiais e orçamentários para deslocamento dos Auditores Fiscais do Trabalho (AFT) do projeto. Não serão inseridas neste projeto empresas com menos de 100 empregados, pois não estão contempladas no Art. 93, da Lei no 8.213/91.

$\mathrm{Na}$ Superintendência no Ceará não há previsão no projeto de qualquer análise em relação à Segurança e Saúde, pretende-se obter a correta adequação das atividades às especificidades das pessoas com deficiência/reabilitadas, bem como eliminar eventuais açóes que consubstanciem assédio moral contra estes trabalhadores. Este tópico depende, para a plena efetividade, da designação de auditores com conhecimentos especiais, em caráter permanente.

Verificando o projeto apresentado pela Superintendência Regional de Pernambuco verifica-se que a coordenação do projeto daquele órgão, solicita a inclusão de um auditor médico para esse trabalho. Justifica o seu pedido para que o profissional, entre outras atividades: faça a análise de laudos médicos caracterizadores de pessoas com deficiência; participe de contatos e mediaçóes com profissionais da área de saúde e analise a adequação de funções às deficiências e restrições.

Ações decorrentes de denúncias acerca de discriminação e assédio moral contra pessoas com deficiência ou reabilitadas, devem ser realizadas, prioritariamente, por meio de mediações e ações fiscais diretas. Deve-se ter sempre a preocupação com a mudança cultural da visão das empresas em relação às pessoas com deficiência.

A inclusão de pessoas com deficiência no Mercado de Trabalho está dentro dos compromissos nacionais do Ministério do Trabalho e Previdência Social. Não é atividade acessória da Fiscalização do Trabalho, mas sim de caráter essencial;

A inclusão de empregados com deficiência/reabilitados decorre da verificação fática que os mesmos são discriminados no acesso ao mercado de trabalho e consagra os dispositivos constitucionais de promoção da dignidade da pessoa humana, em sua vertente de tra- 
balhador com deficiência/reabilitado, de combate à discriminação e o assédio moral contra os trabalhadores deste segmento, e de respeito ao valor social do trabalho.

Por se tratar de uma atividade com uma grande relutância de cumprimento por parte das empresas, com natureza de política pública/ação afirmativa, torna-se necessária, para a efetividade/permanência dos resultados obtidos, além da fiscalização propriamente dita, uma série de outras açóes, de forma a promover a igualdade de tratamento, não só pela contratação, mas também no curso da relação empregatícia. As empresas que já tiveram açôes de conscientizaçáo serão tratadas com maior rigidez, em relação à lavratura de auto de infração e concessão de prazos para regularização.

Ressalte-se também que as alterações advindas da Lei 12.470/2011 promoveram radicais modificaçóes na inclusão de pessoas com deficiência no mundo do trabalho. Entre as principais alteraçóes, podemos citar o novo conceito de deficiência que apenas sob a ótica médica, incorporando as barreiras atitudinais, que dificultam a inclusão no mercado de trabalho.

Ressalte-se também que no texto alterado, a inclusão da expressão "mental", sem menção a qualquer graduação, certamente estimulará a tentativa de incluir na reserva legal certos transtornos mentais que, de per si, não deveriam caracterizar deficiência. A extrema abertura do conceito ensejará a necessidade de atenção redobrada e, na medida do possível, a uniformização de decisões em situaçóes similares, de modo a se evitar mandados de segurança pela denegação de classificação como pessoa com deficiência.

Como positivo, as alteraçôes legais permitirão que certas categorias anteriormente não abrangidas na lei, mas que são vítimas de discriminação, como visão monocular, gagueira grave, deformidades faciais graves possam vir a ser consideradas como deficiência.

Mera suspensão do Benefício de Prestação Continuada-BPC, na contratação de empregado com deficiência e desnecessidade de submeter-se à nova perícia para fins de retorno de percepção do BPC, em caso de afastamento de emprego. Estima-se que o impacto desta alteração legal será substancial.

Uma das maiores reclamaçôes dos empresários, ao argumentar a dificuldade de contratar pessoas com deficiência aptas ao trabalho, era que muitos se recusavam a serem registrados, em face do medo de perder definitivamente a percepção do benefício. Agora está bastante claro que o BPC será meramente suspenso enquanto persistir o vínculo empregatício. Para a retomada do benefício, sequer será necessária a realização de nova perícia, a qual só será exigida por ocasião do lapso temporal previsto para a reavaliação de cada beneficiário (02 anos).

Esta nova possibilidade estimulará a inclusão de pessoas com deficiência por meio da aprendizagem, a qual independe de idade para a pessoa com deficiência, vez que além de não perder o BPC, passará a recebê-lo em conjunto com a remuneração da aprendizagem. Há necessidade de, além de estimular as pessoas com deficiência e os empregadores para a adoção deste caminho, também requerer que a Rede $S$ modifique a sua atuação, no sentido de receber, em maior intensidade, aprendizes com deficiência. Não temos dúvida que a aprendizagem é um dos melhores caminhos para eliminar certos preconceitos por parte dos gestores das empresas, vez que há a oportunidade de conhecer e avaliar os aprendizes com deficiência durante a parte prática do processo de aprendizagem, objetivando sempre a sua contratação de modo definitivo, redução de $30 \%$ para o pensionista com deficiência intelectual que entre no mercado de trabalho e não consideração da remuneração da aprendizagem para fins de cálculo da renda per capita utilizada na concessão de remuneraçóes assistenciais, como o BPC. 
Com estes conceitos bem fundamentos, tornou-se possível avaliar as ações de responsabilidade social aplicadas em uma empresa da área de saúde e mensurar sua importância, eficiência e relevância no que diz respeito a ser um canal de transmissão da preocupação social da instituição para seus colaboradores portadores de deficiência física.

Quanto ao perfil dos colaboradores do Hospital Y que responderam o questionário da pesquisa em questão, pode-se dizer que todos estão contratados pela própria empresa; destes, $60 \%$ são homens.

Dos entrevistados, $70 \%$ cursaram o ensino médio, $20 \%$ o ensino fundamental e $10 \%$ o ensino superior.

Em sua maioria, que corresponde a $60 \%$ do total, não conhecem a Lei das Cotas para Pessoas Portadoras de Deficiências (Lei n 8.213/91), seguidos de 20\% dos colaboradores, que afirmaram conhecer pouco esta Lei; $10 \%$ disse conhecer razoavelmente e outros $10 \%$ afirmou conhecer bastante.

Percebe-se através destes números que os colaboradores, em sua maioria, não possuem ensino médio completo e desconhece as leis que os asseguram. Conforme o Estatuto do Deficiente Físico prevê em uma de suas diretrizes, a organização deve ofertar a provisão de suportes individualizados, de forma que atenda às necessidades da pessoa com deficiência. Diferente disto, verifica-se que a maioria dos colaboradores possui apenas o ensino médio e desconhece a jurisdição que lhes respalda, apesar de terem externado nas sugestóes de açôes de responsabilidade social por parte do Hospital Y (questão 11) o desejo de uma bolsa-educação, no intuito de se profissionalizarem e de estarem cada vez melhor inseridos na instituição e na sociedade, como um todo.

Questionados sobre a adequação do emprego às suas competências e conhecimentos, $60 \%$ respondeu que não se sentem bem alocados, ou seja, acreditam que suas funçóes não condizem que as suas habilidades.

Outra diretriz que o Estatuto do Deficiente Físico prevê é a participação, de forma viável, dos deficientes nas organizaçóes da sociedade civil. Esta diretriz não está em vigor, já que a maior parcela de funcionários deficientes se sente mal alocada, ou seja, não acreditam que estejam desempenhando funçóes de acordo com as suas características corporais.

As aplicaçóes do questionário possuem fatores limitantes que devem ser levados em consideração. Uma limitação que se deriva das pesquisas exploratórias, é que essas dependem do pesquisador com base nas respostas obtidas. As interpretações das análises dos entrevistados podem sofrer influências no momento da análise do aplicador do questionário.

Outro fator limitante é o número de pessoas entrevistadas, no caso dez, envolvendo todos os colaboradores portadores de deficiência física. Apesar de ser um número viável, pelo fato de abranger todo o extrato de profissionais existe no hospital Y e pela evidenciação de repetiçóes nas respostas apresentadas pelos entrevistados, não possibilita a generalização da pesquisa.

A presente pesquisa tinha o objetivo de realizar um estudo exploratório, e como é de natureza dos estudos exploratórios, abre a possiblidade para novos estudos futuros. Dada à limitação de abrangência da pesquisa, sugere-se então a reaplicação da mesma em outras empresas de mesmo setor, de maneira que haja aumento da amostra probabilística, possibilitando a sua generalização.

Por fim, considerando as mudanças que constantemente ocorrem nas empresas e nos seus métodos de gestão, principalmente em empresas de médio e grande porte, há a necessidade de reaplicar essa pesquisa para percepção de mudanças significativas nas açóes de responsabilidade social quanto ao trabalho de deficientes físicos. 
Desde 2002, o SENAC desenvolve um programa nacional voltado para a inclusão de pessoas com deficiência, por meio da educação profissional. Com isso, promove a reinserção desses brasileiros no mercado de trabalho e, consequentemente, uma melhoria na qualidade de vida de todas elas. Anteriormente chamado de "Deficiência \& Competência", o programa estratégico para a Instituição, ganhou, em 2010, novo nome: Programa Senac de Acessibilidade (PSA). Assim, o Senac amplia o seu trabalho e aprimora sua programação para atender uma grande parcela da população brasileira. Assim, o Senac tem investido na preparação de profissionais capazes e competentes para atender à exigência legal. No Senac, as deficiências não são barreiras. Esse público é atendido na programação regular, a fim de incentivar a integração. Somente quando solicitado por alguma organização parceira, turmas especiais são abertas. (SENAC, 2012).

O governo deve promover incentivos para que a população de deficientes, receba treinamento como o do SENAC e seja inserida no mercado de trabalho de forma viável, levando em consideração o tipo e grau de suas deficiências. Além disso seria de notória importância o aumento da fiscalização nas empresas, para concluir se, além de cumprirem com o número de contrataçóes previstos de acordo com o total de funcionários, estão realizando treinamentos para inclusão dos portadores de deficiência na empresa e alocando de forma correta, de acordo com a deficiência de cada colaborador e sua funçáo desempenhada na empresa, promovendo a integração e inclusão destes nas instituiçóes.

\section{CONSIDERAÇÕES FINAIS}

Por meio dos dados tabulados e apresentados, constatou-se que a instituição não apresenta açóes sólidas de responsabilidade social voltadas aos colaboradores deficientes físicos.

É possível afirmar que a contratação destes funcionários ocorreu de forma a contemplar a Lei somente e que não houve, assim, subsídios para se chegar a definição do conceito de SER.

É notória a omissão por parte da empresa, com relação as ações de responsabilidade social que poderiam e deveriam ser implantadas e desenvolvidas. Através das respostas dos colaboradores foi possível concluir que há uma deficiência e negligência no cuidado com os funcionários portadores de deficiência física, o que pôde ser analisado, fortemente, através dos dados obtidos nas questóes 4, 5, 7, 8 e 9 .

Com os dados destas questôes, concluiu-se que a empresa não prepara treinamento específico para colaboradores com deficiência; não realiza a análise das competências destes colaboradores para a função a ser desempenhada, de acordo com suas características corporais; não se dispõe a realizar adaptaçóes sólidas em sua estrutura física, a fim de melhorar o acesso de seus colaboradores e não realiza açóes de inclusão destes colaboradores, como criação de grupos, comitês, definição de cronograma de ações para a recepção, dentre outras.

As organizações que almejam um diferencial no mercado buscam cada vez mais estratégias para conquistar novos clientes, visando o envolvimento da sociedade em suas estratégias. As tendências apontam que uma ótima alternativa para isso é a diferenciação, sendo a responsabilidade social a que está em maior evidência.

Voltando o olhar para seus colaboradores deficientes, as instituiçóes estarão ao mesmo tempo investindo em seu próprio benefício e desenvolvimento, pois a sinergia gerada a partir daí pode aproximar público e empresa de forma mais concreta e efetiva, em uma ver- 
dadeira relação "ganha-ganha". Portanto, o que é desenvolvido para a melhoria da sociedade pode ser utilizado como uma ferramenta de marketing.

As organizaçóes devem desenvolver o seu marketing social e mostrar todos os investimentos aplicados em certificações, normas e implantações de sistemas adaptados aos funcionários deficientes, por exemplo. Essas atitudes geram uma imagem positiva da empresa perante o seu público e a sociedade. Conseguir envolver os colaboradores com deficiência da organização e comprometê-los também com o papel social é o novo desafio proposto e fundamental para o sucesso de qualquer estratégia. Para que isto ocorra, é necessário que tenham consciência em reconhecer e motivar quem é a peça-chave de todo este processo, ou seja, seus próprios colaboradores.

\section{REFERÊNCIAS}

BARTON, Len; OLIVER, Mike. The birth of disability studies. Leeds: The Disability Press, 1997.

BRASIL. Decreto 3.298, de 20 de dezembro de 1999. Regulamenta a Lei no 7.853, de 24 de outubro de 1989, dispóe sobre a Política Nacional para a Integração da Pessoa Portadora de Deficiência, consolida as normas de proteção, e dá outras providências. Disponível em: http://www.planalto.gov.br/. Acesso em: 14 fev. 2016.

BRASIL. Decreto 3.956, de 08 de outubro de 2001. Promulga a Convenção Interamericana para a Eliminação de Todas as Formas de Discriminação contra as Pessoas Portadoras de Deficiência. Disponível em: http://www.planalto.gov.br/. Acesso em: 14 fev. 2016.

BRASIL. Decreto Legislativo No 186. Aprova o texto da Convenção sobre os Direitos das Pessoas com Deficiência e de seu Protocolo Facultativo, assinados em Nova Iorque, em 30 de março de 2007. Disponível em: http://www.planalto.gov.br/. Acesso em: 14 fev. 2016.

BRASIL. Decreto n. 6949, de 25 de agosto de 2009. Promulga a Convenção Internacional sobre os Direitos das Pessoas com Deficiência e seu Protocolo Facultativo, assinados em Nova York, em 30 de março de 2007. Disponível em: http://www.planalto. gov.br/. Acesso em: 14 fev. 2016.

BRASIL. Emenda Constitucional n. ${ }^{\circ}$ 45, de 31 de dezembro de 2004. Altera dispositivos dos arts. 5०, 36, 52, 92, 93, 95, 98, 99, 102, 103, 104, 105, 107, 109, 111, 112, 114 , $115,125,126,127,128,129,134$ e 168 da Constituição Federal, e acrescenta os arts. 103-A, 103B, 111-A e 130-A, e dá outras providências. Disponível em: http:// www.planalto.gov.br/. Acesso em: 14 fev. 2016.

BRASIL. Lei 11.180, de 23 de setembro de 2005. Institui o Projeto Escola de Fábrica, autoriza a concessão de bolsas de permanência a estudantes beneficiários do Programa Universidade para Todos - PROUNI, institui o Programa de Educação Tutorial PET, altera a Lei n ${ }^{\circ} 5.537$, de 21 de novembro de 1968, e a Consolidação das Leis do Trabalho - CLT, aprovada pelo Decreto-Lei $\mathrm{n}^{\circ} 5.452$, de $1^{\circ}$ de maio de 1943 , e dá outras providências. Disponível em: http://www.planalto.gov.br/. Acesso em: 14 fev. 2016.

BRASIL. Lei 12.470, de 31 de agosto de 2011. Acrescenta o art. 21-A à Lei no 8.742, de 7 de dezembro de 1993 - Lei Orgânica de Assistência Social, para alterar regras do 
benefício de prestação continuada da pessoa com deficiência. Disponível em: http:// www.planalto.gov.br/. Acesso em: 14 fev. 2016.

BRASIL. Lei 13.146, de 6 de julho de 2015. Institui a Lei Brasileira de Inclusão da Pessoa com Deficiência (Estatuto da Pessoa com Deficiência). Disponível em: http://www. planalto.gov.br/. Acesso em: 29fev. 2016.

BRASIL. Lei 7.853, de 24 de outubro de 1989. Dispóe sobre o apoio às pessoas portadoras de deficiência, sua integração social, sobre a Coordenadoria Nacional para Integração da Pessoa Portadora de Deficiência - Corde, institui a tutela jurisdicional de interesses coletivos ou difusos dessas pessoas, disciplina a atuação do Ministério Público, define crimes, e dá outras providências. Disponível em: http://www.planalto.gov.br/. Acesso em: 14 fev. 2016.

BRASIL. Lei 8.213, de 24 de julho de 1991. Dispóe sobre os Planos de Benefícios da Previdência Social e dá outras providências. Disponível em: http://www.planalto.gov. br/. Acesso em: 14 fev. 2016.

BRASIL. Lei 8.666/93, de 21 de junho de 1993. Regulamenta o art. 37, inciso XXI, da Constituição Federal, institui normas para licitaçôes e contratos da Administração Pública e dá outras providências. Disponível em: http://www.planalto.gov.br/. Acesso em: 14 fev. 2016.

BRASIL. Projeto de Lei 7.699/06, de 21 de dezembro de 2006. Institui o Estatuto do Portador de Deficiência e dá outras providências. Disponível em: www2.camara.leg. br. Acesso em: 14 de fev. 2016.

CENSO DEMOGRÁFICO 2010. Características da população e dos domicílios: resultados do universo. Rio de Janeiro: IBGE, 2011. Disponível em: http://censo2010. ibge.gov.br/. Acesso em: 29 fev. 2016.

CENSO DEMOGRÁFICO 2010. Características gerais da população, religião e pessoas com deficiência. Rio de Janeiro: IBGE, 2012. Disponível em: http://censo2010.ibge. gov.br/. Acesso em: 29 fev. 2016.

COUTINHO, R. B. G.; MACEDO-SOARES, T. D. L. V. A. Gestão estratégica com responsabilidade social: arcabouço analítico para auxiliar sua implementação em empresas no Brasil. Revista de administraçáo contemporânea, Curitiba, v. 6, n. 3, set./dez. 2002. Disponível em: http://www.scielo.br/scielo.php?pi$\mathrm{d}=S 141565552002000300005 \&$ script $=$ sci_arttext $\&$ tlng=en. Acesso em: $10 \mathrm{fev}$. 2017.

FIGUEIRA, Emilio. Caminhando em silêncio: - Uma introdução à trajetória das pessoas com deficiência na História do Brasil. São Paulo: Giz Editorial, 2008.

INSTITUTO BRASILEIRO GEOGRAFIA E ESTATÍSTICA - IBGE. CENSO 2000 Dados preliminares. Rio de Janeiro: IBGE, 2000. Disponível em: www.ibge.gov.br. Acessado em: 29 fev. 2016.

MAZZOTTA, Marcos J. Trabalho Docente e Formaçáo de Professores de Educaçáo Especial. São Paulo: EPU, 1993.

MAZZOTTA, Marcos José Silveira. Educaçáo especial no Brasil: História e políticas. 3. ed. São Paulo: Cortez, 2001.

MINTZBERG, H. (1983). Power in and Around Organizations. Prentice-Hall, INC., Englewood Cliffs, N.J. 
ORGANIZAÇÃO DAS NAÇÓES UNIDAS (ONU). Convenção Internacional sobre os Direitos das Pessoas com Deficiência. Disponível em: www.pessoacomdeficiencia. gov.br. Acesso em: 21 fev. 2016.

ORGANIZAÇÃO DAS NAÇŌES UNIDAS (ONU). Declaraçáo dos direitos das pessoas deficientes. Disponível em: portal.mec.gov.br/seesp/arquivos/pdf/dec_def. pdrf. Acesso em: 14 fev. 2016.

ORGANIZAÇÃO DAS NAÇÓES UNIDAS (ONU). Declaração Universal dos Direitos Humanos. Disponível em: http://www.dudh.org.br/declaracao/. Acesso em: 14 fev. 2016.

PORTER, M. E.; KRAMER, M. R. Strategy \& Society: The Link between Competitive Advantage and Corporate Social Responsibility. Harvard Business Review, v. 84, p. 78-85. 2006.

SILVA, Otto Marques. A Epopeia Ignorada: a pessoa deficiente na história do mundo de ontem e de hoje. São Paulo: Cedas, 1987. Apud: CARMO, Apolônio Abadio do. Deficiência Física: A realidade brasileira cria, recupera e discrimina. Brasília: MEC/ Secretaria dos Desportos, 1991.

SOUSA FILHO, J. M.; WANDERLEY, L. S. O. Divulgação da responsabilidade social empresarial: como os websites empresariais vêm sendo utilizados por empresas de energia e varejo. In: Anais do XXX Encontro da ANPAD. Salvador: EnANPAD, 2006.

\section{Alexandre Antonio Bruno da Silva}

alexandre_bruno@terra.com.br

Possui graduação em Processamento de Dados pela Universidade Federal do Ceará (1988), graduação em Direito pela Universidade de Fortaleza (1998), mestrado em Informática pela Pontifícia Universidade Católica do Rio de Janeiro (1991), mestrado em Direito (Direito e Desenvolvimento) pela Universidade Federal do Ceará (2001) e doutorado em Direito pela Pontifícia Universidade Católica de São Paulo (2005). Atualmente é professor adjunto da Universidade Estadual do Ceará (UECE), professor do Centro Universitário Christus (UNICHRISTUS), coordenador da pós-graduação em direito do trabalho do Centro Universitário Christus (UNICHRISTUS), auditor-fiscal do trabalho do Ministério do Trabalho e Emprego, professor titular da Faculdade Farias Brito (FB). Tem experiência na área de Direito, com ênfase em Direito Sociais, atuando principalmente nos seguintes temas: teoria geral do direito, direitos fundamentais sociais, relaçóes de trabalho, responsabilidade social empresarial e filosofia do direito.

\section{Vanessa Guimarães Romão}

by_vanessaguimaraes@gmail.com

Bacharel em Administração pela Universidade Estadual do Ceará 